\title{
Pengaruh kualitas pelayanan dan kepuasan anggota terhadap loyalitas anggota pada Lembaga Keuangan Baitul Maal Wat Tamwil (BMT) Indragiri di Kabupaten Indragiri Hulu
}

\author{
Ayu Kartika ${ }^{1^{*}}$, Rosmayani $^{2}$, Ujang Paman ${ }^{3}$ \\ ${ }^{1,2,3}$ Universitas Islam Riau \\ *Correspondentemail : artikaayu25@gmail.com
}

\begin{abstract}
This study aims to determine the effect of service quality and member satisfaction on member loyalty at the Baitul Maal Wat Tamwil Indragiri Financial Institution. The analysis method used in this research is Data Quality Test, Multiple Linear Regression Analysis, Hypothesis Test and Classical Assumption Test. In this study, it can be concluded that the quality of services provided and the satisfaction obtained by members of the Indragiri BMT Financial Institution can generate Member Loyalty and become a value for members to always survive and be loyal to the Financial Institutions BMT Indragiri. From testing the results of data analysis in this study, the data quality test results obtained from the validity and reliability tests on the variable service quality, member satisfaction and member loyalty declared valid and reliable, as evidenced by the validity test which shows that each item value is greater than the rtabel value. 0.208 . Whereas the reliability test proves that the data is reliable with 20 instrument values which state the value is greater than the r table. The results of multiple linear regression analysis between service quality, member satisfaction and member loyalty obtained the value of $Y==4,541+0.109 X 1+0.243 X 2$. From the research results obtained $R 2$ value of 0.221 , which means that the variable service quality, member satisfaction has a positive and significant simultaneous influencer of $22.1 \%$ of members on member loyalty. In testing the hypothesis, namely the F test, it can be seen that together these three variables had a positive and significant simultaneous effect because the value of Fcount $>$ Ftable $(12,203>3,10)$. In the $t$ test, to test the effect of the three variables, namely service quality and member satisfaction, the service quality variables had the most dominant influence on member loyalty. Where, the count value of the service quality variable (X1) is the largest compared to the member satisfaction variable, which is 3,902 .
\end{abstract}

Keywords: Service quality; Member loyalty; Baitul Maal Wat Tamwil (BMT)

Pertumbuhan ekonomi suatu bangsa memerlukan suatu pola pengolahan sumber ekonomi yang tersedia secara terarah dan terpadu serta dimanfaatkan secara penuh bagi kesejahteraan seluruh masyarakat. Tersedianya sumber daya alam, modal dan teknologi merupakan jaminan bahwa kemajuan akan diraih secara gemilang. Pada perusahaan yang menjual jasa hal utama yang harus di prioritaskan oleh perusahaan adalah mengambil inisiatif bagaimana cara meningkatkan pelayanannya agar dapat menyesuaikan diri sesuai dengan kebutuhan dan harapan pelanggan/nasabah.

Lembaga keuangan di Indonesia sendiri memberikan contribusi yang signifikan terhadap pertumbuhan ekonomi dan kesejahteraan masyarakat, karenanya lembaga keuangan harus menjadi suatu alat sebagai penunjang pertumbuhan ekonomi masyarakat.Lembaga keuangan terdiri dari lembaga keuangan konvensional dan lembaga keuangan non konvensional.Lembaga keuangan konvensional merupakan lembaga yang sepenuhnya menjalankan kegiatan usaha secara umum berdasarkan prosedur dan ketentuan yang telah ditetapkan oleh pemerintah dan Negara. Sedangkan lembaga keuangan non konvensional itu sendiri dalam pembahasan ini adalah merupakan lembaga keuangan yang menjalankan ketentuan dan prosedurnya tidak memiliki keterikatan terhadap pemerintah dan Negara, salah satunya adalah lembaga keuangan syariah. Lembaga keuangan syariah merupakan suatu bentuk lembaga keuangan non konvensional yang menjalankan tanggung jawab berbasis Islamiah. Dengan upaya penyehatan sistem perbankan nasional, maka hadirlah Lembaga Keuangan Berbasis Syariah Muamalat Indonesia. Upaya pengembangan Perbankan Syariah di Indonesia sebenarnya bukan hanya merupakan konsekuensi yuridis Undang-Undang Perbankan dan Undang-Undang BI saja, akan tetapi merupakan 
bagian yang tidak terpisahkan dari upaya penyehatan sistem perbankan nasional yang bertujuan meningkatkan daya tahan perkonomian nasional.

Pertumbuhan setiap Lembaga Keuangan berkaitan dengan kualitas pelayanan yang diberikan, yang harus diperhatikan pihak Lembaga Keuangan untuk memotivasi agar dapat meningkatkan eksistensi dan meningkatkan pertumbuhan ekonomi masyarakat umat Islam. Dimana Lembaga Keuangan Syariah yang sedang berkembang dengan pesat. Kualitas pelayanan merupakan faktor kunci daya saing di dunia perbankan. Memenangkan persaingan Perbankan Syariah dalam menghadapi lingkungan bisnis yang sangat kompetitif agar tetap bertahan atau eksis salah satunya dengan cara memberikan pelayanan nasabah dengan baik.

Salah satunya dalam penyediaan jasa keuangan berbasis syariah adalah lembaga keuangan Baitul Maal Wat Tamwil (BMT) Indragiri. Baitul Maal Wat Tamwil (BMT)adalah Lembaga Keuangan Mikro (LKM) yang beroperasi berdasarkan prinsip-prinsip syariah. BMT sesuai dengan namanya terdiri dari dua fungsi utama, yaitu:

Baitul Maal (Bait = Rumah, Maal=Harta) dimaksudkan sebagai Lembaga Amil Zakat (LAZ) sebagaimana kemudian muncul UU No. 38/1999 yaitu menerima titipan dana Zakat, Infaq dan Shadaqah serta mengoptimalkan distribusinya sesuai dengan peraturan dan amanahnya. Dikelola secara professional, transparan dan sesuai dengan kaidah Syariah. Peran sebagai wadah dalam pemberdayaan potensi ummat Islam.

Eksistensi lembaga keuangan berbasis syariah BMT Indragiri ini jelas memiliki arti penting bagi pembangunan ekonomi berwawasan syariah terutama dalam memberikan solusi bagi pembangunan ekonomi , bagi pemberdayaan usaha kecil dan menengah serta menjadi kekuatan ekonomi yang berbasis kerakyatan dan sekaligus menjadi tonggak utama sistem perekonomian islamiah daerah Kabupaten Indragiri Hulu.

Terkait dimensi kualitas pelayanan yang diberikan lembaga keuangan Baitul Maal Wat Tamwil Indragiri diantaranya, Tangibels, yang menjelaskan kondisi fisik lembaga keuangan, seperti bangunan fisik BMT indragiri yang dulunya terletak di mesjid, menjadi berkembang bisa menyewa bangunan ruko, dan di tahun 2019 awal lembaga keuangan syariah BMT Indragiri ini sudah memiliki bangunan sendiri. Lokasi parkir dan ruangan tunggu yang sangat nyaman, pakaian karyawan yang rapidan sopan, serta pemberian pelayanan yang ramah kepada anggota.Emphat:kemudahan dalam melakukan hubungan komunikasi dengan sistem kekeluargaan. Kepuasan nasabah tentu tidak lepas dari pelayanan lembaga keuangan.Realibility: kemampuan lembaga keuangan yang memberikan service terbaik yang berbentuk pelayanan secara akurat, transparan, bertanggung jawab dan dapat dipercaya.Responsiveness:ketanggapan/keinginan membantu nasabah memberikan produk simpanan dan pinjaman yang mudah dan mudah dipahami dan kondisi lingkungan sosial masyarakat. Terakhir adalah Assurance:dimana lembaga keuangan BMT Indragiri mampu memberikan jaminan pembiayaan kepada anggota yang melakukan transaksi pembiayaan.

Parasuraman dalam Lupiyoadi. (2008) kualitas pelayanan didasarkan pada lima dimensi yaitu Tangible, Realibility, Responsivess, Assurance dan Emphaty.

Wyekot, Arief (2007) mengungkapkan bahwa pengertian kualitas pelayanan sebagai tingkat kesempurnaan dan pengendalian akan kesempurnaan tersebut untuk memenuhi keinginan pelanggan.

Pelayanan juga diartikan dengan jasa, kualitas jasa merupakan suatu pembahasan yang sangat komleks karena penilaian kualitas pelayanan berbeda dengan kualitas produk, terutama sifatnya yang tidak nyata (intangible), sehingga kualitas pelayanan adalah bagaimana tanggapanpelanggan terhadap jasa yang dikonsumsi atau dirasakan Jasfar. (205:47)

Keberadaan Lembaga Keuangan Baitul Maal Wat Tamwil (BMT) Indragiri di Kota Rengat sesungguhnya merupakan potensi penggerak ekonomi yang cukup signifikan di kota Rengat. Hal itu disebabkan BMT Indragiri secara konseptualnya mengarahkan usaha kecil yang lahir dan tumbuh dari kalangan masyarakat menengah kebawah, Di sisi lain lembaga keuangan BMT Indragiri bertujuan untuk mengembangkan perekonomian masyarakat Islam yang dikemas dalam bentuk dakwah islami agar masyarakat Islam di kota Rengat mengerti ajaran sesungguhnya Rasulullah SAW yang sahih. Kepuasan anggota timbul dari kualitas pelayanan dan produk yang diberikan berbeda dengan lembaga keuangan lainnya, sehingga anggota yang merasa puas akan melakukan transaksi berulang-ulang dengan menggunakan produk yang ditawarkan oleh lembaga keuangan Baitul Maal Wat Tamwil (BMT) Indragiri Kehadiran BMT Indragiri hingga kini belum maksimal dalam mengembangkan produk yang dimilikinya. Sebaliknya beberapa kelemahan yang dialami oleh lembaga keuangan BMT Indragiri yang masih relatife baru ini, kini menjadi peluang sekaligus tantangan bagi pihak-pihak terkait untuk tetap bisa memanfaatkan dan mempertahankan eksistensinya dalam menjalankan tujuannya yaitu mengembangkan perekonomian masyarakat Islam dengan jalan dakwah. 
Beberapa kelemahan yang dialami oleh lembaga keuangan BMT Indragiri yaitu berkisar pada lemahnya sumber daya manusia yang dimiliki, karena SDM yang direkrut tidak melalui pelatihan(training) atau memiliki kriteria tertentu,melainkan direkrut secara terbuka dan otodidak untuk menjalankan perekonomianIslam.Selain itu, SOP manajemen yang ditetapkan juga belum diterapkan secaramaksimal. SOP yang telah direncanakan guna sebagai pemberian layanan yang berkualitas kepada anggota agar tercapainyalembaga keuangan yang representative,efektif dan efisien.

Kelemahan-kelemahan tersebut pada gilirannya akan berujung kepada sulitnya menumbuhkan suatu kepercayaan baik kepada pihak yang memberikan modal ataupun kepada anggota yang menggunakan modal. Namun demikian konsep pemasaran saat ini telah bergeser dari product oriented menjadi costumer oriented (orientasi konsumen), dimana tidak hanya mmeperhatikan mutu dan produknya saja, melainkan juga memperhatikan kepuasan anggotanya. Bentuk dari konsep customer oriented ini adalah lembaga keuangan BMT Indragiri harus lebih memperhatikan anggotanya dengan cara memberikan pelayanan prima dan selalu menjaga hubungan baik sehingga memuaskan keinginan dan kebutuhan anggota BMT Indragiri.

Menurut Kotler. (2000) kepuasan adalah tingkat perasaan seseorang setelah membandingkan kinerja atau hasil yang dia rasakan dibandingkan dengan harapannya. Jadi lembaga keuangan Baitul Maal Wat Tamwil harus mengukur tingkat kepuasan anggota agar nantinya lembaga BMT Indragiri memiliki pelanggan tetap dan terus bisa survive dengan pelayanan berkualitas yang dapat memuaskan kebutuhan anggota.

\section{METODE PENELITIAN}

Adapun metode yang penulis gunakan dalam penelitian adalah metode deskriptif kuantitatif., Menurut Sugiyono (2013:13), metode penelitian kuantitatif adalah : "Metode penelitian kuantitatif dapat diartikan sebagai metode penelitian yang berlandaskan pada filsafat positivisme, digunakan untuk meneliti pada populasi atau sampel tertentu, teknik pengambilan sampel pada umumnya dilakukan secara random, pengumpulan data menggunakan instrumen penelitian, analisis data bersifat kuantitatif/statistik dengan tujuan untuk menguji hipotesis yang telah ditetapkan." Observasi mendalam dilakukan pada informan penelitian ini teknik Insidential sampling yaitu penentuan sampel berdasarkan kebetulan yang bertemu dengan sipenliti dilapangan yaitu di lembaga keuangan BMT Indragiri.

Penentuan sampel menggunakan rumus slovin. Dari 89 orang tersebut diambil dengan alasan populasi $800 /(1+(800 \times 0,01)=800 / 9=89$.

\section{HASIL DAN PEMBAHASAN}

Lembaga Keuangan Baitul Maal Wat Tamwil Indragiri ini sudah berupaya memberikan Pelayanan yang Berkualitas dan Kepuasan Anggota yang maksimal sehingga terciptanya Loyalitas Anggota yang meningkat dari tahun ke tahun. Eksistensi ini mampu survive karena adanya mobilisasi penggerak dari karyawan BMT Indragiri beserta stakeholder-nya. Pelayanan yang diberikan tentunya tidak terlepas dari konsep TERRA yang mempunyai 5 indikator yang signifikan terhadap output nya yaitu loyalitas anggota. Konsep TERRA tersebut yaitu : Tangibles yang mengartikan bahwasannya kondisi fisik menjelaskan dan menggambarkan memberikan aspek fundamental yang membuat anggota merasakan kenyamanan untuk melakukan transaksi secara berkesinambungan dari hari ke hari. Indikator kedua adalah Emphaty dimana indikator ini menunjukkan bahwasannya tingkat kepedulian karyawan BMT Indragiri ini sangatlah tinggi dengan dibuktikan oleh kenyamanan anggota yang melakukan transaksi dengan memberikan pelayanan yang tidak diskriminatif yang selalu mendahulukan kepentingan anggota. Indikator yang ketiga yaitu Responsivess, dimana indikator ini menjelaskan bahwa respon cepat tanggap dan pemberian informasi yang jelas kepada anggota adalah suatu bentuk pelayanan yang maksimal.

Indikator ke empat yaitu Reliability yang mana indikator ini menjelaskan bahwa karyawan BMT Indragiri memberikan standar informasi yang jelas dalam memberikan informasi yang akurat dan reliabel.pada indikator kelima yaitu Assurance yang mana indikator ini menjelaskan bahwa pihak BMT Indragiri memberikan jaminan harga maupun jaminan jasa yang nantinya akan menghasilkan suatu bentuk kepercayaan baik pada pihak BMT Indragiri maupun anggota BMT Indragiri. Kepuasan anggota yang diperoleh olehanggota tentunya tidak terlepas dari usaha-usaha dalam memaksimalkan pelayanan yang berkualitas. Kepuasan anggota tersebut dibuktikan dengan memberikan produk produk BMT Indragiri, selain itu kepuasan anggota yang diraih juga sangat berkorelasi terhadap pelayanan yang diberikan. Serta kepuasan anggota yang dihasilkan dari fasilitas yang disediakan oleh pihak BMT Indragiri. Saat Lembaga Keuangan BMT Indragiri beserta stakeholder-nya memberikan pelayanan yang berkualitas dan Kepuasan Anggota maka akan terciptanya Loyalitas Anggota yang menjadi suatu hal yang 
sangat signifikan dalam mempertahankan eksistensi dan survive nya Lembaga Keuangan BMT Indragiri tersebut. Loyalitas yang diperoleh oleh anggota BMT Indragiri tentunya adalah suatu hal yang harus dipertahankan oleh pihak BMT Indragiri beserta stakeholder-nya, yang mana loyalitas anggota dapat dibuktikan dengan adanya transaksi secara berulang yang dilakukan oleh anggota BMT Indragiri, selain itu dibuktikan oleh adanya promosi secara gratis, (worth of mouth communication) yang dihasilkan dari terpenuhinya kepuasan anggota yang menghasilkan transaksi secra berulang-ulang dan mengajak orang lain untuk menggunakan produk BMT dan menjadi anggota BMT Indragiri.

Dengan meningkatkan kualitas pelayanan dan kepuasan anggota yang akan menghasilkan loyalitas anggota tentunya pihak BMT Indragiri beserta stakeholder-nya harus tetap menggenjot dan berupaya dalam mengoptimalkan sumberdaya manusia yang dimiliki dan menjalankan SOP sesuai fungsinya agar terciptanya tujuan yang efektif dan efisien.

\section{KESIMPULAN}

Berdasarkan hasil analisis data tersebut diatas dapat diambil kesimpulan sebagai berikut:

Pengujian secara parsial diperoleh hasil bahwa terdapat variabel yang paling dominan mempengaruhi loyalitas anggota adalah variabel kualitas pelayanan $\left(\mathrm{X}_{1}\right)$ dengan nilai $t_{\text {hitung }}$ yang paling besar tiga koma sembilan kosong dua.Dikarenakan pengaruh dari variabel kualitas pelayanan $\left(\mathrm{X}_{1}\right)$ yang sangat dominan, maka nampak pada hasil pengujian uji t, variabel independen yang lain yakni kepuasan anggota $\left(\mathrm{X}_{2}\right)$, yang tampak mempunyai pengaruh yang lebih kecil terhadap loyalitas anggota Dengan demikian hipotesis pada penelitian ini yang menyatakan dugaan bahwa variabel kualitas pelayanan $\left(\mathrm{X}_{1}\right)$ merupakan variabel yang paling dominan berpengaruh terhadap loyalitas anggota.

Pengujian secara simultan diperoleh hasil variabel bebas yakni kualitas pelayanan dan kepuasan anggota secara simultan berpengaruh positif dan signifikan terhadap variabel terikatnya yakni loyalitas anggota, karena nilai $F_{\text {hitung }}>F_{\text {tabel }}$ yaitu dua belas koma dua kosong tigas lebih besar dari tiga koma sepuluh.

Berdasarkan pengujian diatas yang telah dilakukan oleh penulis, dapat disimpulkan bahwa variabel Kualitas Pelayanan dan Kepuasan Anggota berpengaruh signifikan terhadap loyalitas anggota terbukti dalam pengujian analisa data yang diteliti oleh penulis.

\section{UCAPAN TERIMAKASIH}

Dalam penerbitan Jurnal Penelitian Bisnis dan Manajemen Vol. 1 No. 1, Mei 2021, proses penelaahan naskah melibatkan beberapa Mitra Bestari. Untuk itu, penuis mengucapkan terima kasih kepada Saputra Mansur, S.E, Lembaga Keuangan BMT Indragiri, Jumat, S.E, Lembaga Keuangan BMT Indragiri dan kepada semua pihak yang telah berkontribusi dalam penelitian ini.

\section{DAFTAR PUSTAKA}

Abdurochman, Muhamad Azmi, Ratih Tresnati dan Dede R Oktini. (2015). "Pengaruh Kualitas Pelayanan terhadap Loyalitas Pelanggan (Studi Kasus pada Green Cake dan Coffee Bandung)". Prosiding Penelitian SPeSIA 2015. 379-385.

Artana, R. S. (2016). "Pengaruh Kualitas Pelayanan terhadap Loyalitas Nasabah pada PD Bank Jogja". PT. Gramedia Pustaka Utama, Jakarta.

Arisutha, D. (2005). "Dimensi Kualitas Pelayanan”. Jakarta: Gramedia Pustaka.

Assegaff Mohammad, (2009). "Pengaruh Kualitas Pelayanan Terhadap Kepuasan Pelanggan (Studi Pada Perusahaan Penerbangan PT.Garuda Di Kota Semarang)". Jurnal Ekonomi dan Bisnis. Vol. 10. No. 2. Juli. Unisulla Semarang.

Atmawati, Rustika dan Wahyudi. (2007). "Analisis Pengaruh Kualitas Pelayanan Terhadap Kepuasan Konsumen pada Matahari Departement Store di Solo Grand Mall” Jurnal Ekonomi dan Bisnis.

Branti, I. (2002). Pengaruh Kualitas Pelayanan Terhadap Kepuasan Pelanggan PT. Telkom Cabang Sragen. FE: UMS..

Darmansyah. (2011). "Kualitas Pelayanan” Jakarta: PT. Gramedia. 
Didin Afifudin., Hendri Tanjung. (2003). “Manajemen Syariah dalam Praktek”, Jakarta:Gema Insani.

Diza., F., S. Moniharapon, dan W.Imelda. (2013). "Pengaruh Kualitas Pelayanan, Kualitas Produk dan Kepercayaan terhadap Kepuasan Konsumen". Jurnal Manajemen dan Bisnis, Vol 07, No 14 Hal 102

Fredy Rangkuti. (2002). "Measuring Costumer Satisfaction". PT. Gramedia Pustaka Utama, Jakarta.

Eljunusi Rahman. (2009). "Pengaruh Atribut Produk Islam dan Kualitas Pelayanan dengan pendekatan Maarketing Syariah terhadap reputation, kepuasan, komitmen, dan loyalitas Nasabah Bank Jateng", Pusat Penalitian IAIN Walisongo Semarang.

Endratama., Dewanto. (2015). "Analisis Pengaruh Kualitas Pelayanan Dan Kepuasan Pelanggan Terhadap Loyalitas Pelanggan Studi Pada Rumah Teh Ndoro Donker". Naskah Publikasi. Surakarta., Fakultas Ekonomi dan Bisnis Universitas Muhamamdiyah Surakarta.

Ghazali Imam., (2005). "Aplikasi Analisis Regresi” dengan Program SPSS, Semarang: UNDIP..

Griffin., Jill. (2005). "Customer Loyalty - How to Earn It, How To Keep It. Kentucky: Graw Hill”.

http://jurnal-sdm.blogspot.com/2009/09/sistem-manajemen-kualitas-qms-definisi.html.

Kotler., P. (2002). Manajemen Pemasaran, Edisi Milenium II. Jakarta: Prenhalindo.

Kotler, P., and Keller, Kevin Lane., (2012). Marketing Management: 14th Edition. New Jersey: Prentice Hall Published.

Mervyn., dan Latifa. (2005). Perbankan Syariah: Prinsip, Praktik, Prospek, Jakarta: PT Serambi Ilmu Semesta.

Mowen, J. C., \& Minor, M. (2005). Consumer Behaviour. Boston: Irwin.

Prasetyo, A. (2008). "Analisis Pengaruh Kualitas Pelayanan Terhadap Kepuasan Nasabah Bmt Kaffah, Yogyakarta"., SEM Institut Yogyakarta.

Prasetyo, Bambang., dan Lina Miftahul Jannah. (2007). Metode Penelitian Kuantitatif, Jakarta: PT Grafindo Persada.

Putro, Shandy Widjoyo.(2014). "Pengaruh Kualitas Layanan Dan Kualitas Produk Terhadap Kepuasan Pelanggan Dan Loya litas Konsumen Restoran Happy Garden Surabaya”. Jurnal Manajemen Pemasaran Vol.2, No. 1, 1-9

Ridwan, H., dan P. Samin. (2015). "Pengaruh Kepercayaan, Kualitas Pelayanan dan Nilai Nasabah terhadap loyalitas Pelanggan pada Bank BNI Jakarta"., Jurnal Manajemen Ekonomi dan Bisnis, Vol 03., No $25 \mathrm{Hal} 114$

Riyadi., (2015). "Analisis Pengaruh Kualitas Pelayanan Dan Kepuasan Konsumen Terhadap Loyalitas Pelanggan Pada Rumah Makan Spesial Sambal Di Surakarta. Artikel Publikasi Ilmiah. Surakarta: Fakultas Ekonomi dan Bisnis Universitas Muhammadiyah Surakarta.

Sally Garar Murti, Edy Yulianto, Kadarisman Hidayat., (2013), "Pengaruh Kualitas Pelayanan terhadap Kepuasan Nasabah pada PT Bank Pembangunan Daerah Jawa Timur". Jakarta: PT. RajaGrafindo Persada.

Sholahuddin M., (2006). Lembaga Ekonomi Dan Keuangan Islam, Surakarta: UMS Press. 
Setyawati Indah., (2009). "Analisis Pengaruh Kualitas Layanan Dan Kepuasan Pasien Terhadap Words Of Mouth (Studi pada Pasien Rawat Jalan RS. Bhakti Wira Tamtama Semarang)". Tesis, Program Studi Magister Manajemen Universitas Diponogoro, Semaran

Syafrina, N. dan S. Akbar., (2019). "Pengaruh Kualitas Pelayanan Banquet terhadap Kepuasan Konsumen pada Labersa Grand Hotel Siak Hulu Kampar", Jurnal Manajemen dan Bisnis, Vol 8, No. 01, Hal 95

Undang-Undang No. 10 tahun 1998 tentang perubahan Undang-Undang No. 7 tahun 1992 tentang Perbankan.

Veithzal, Rivai, dkk., (2007). Bank and Financial Institution Management,. Jakarta: PT Raja Grafindo Persada

Wahyuningsih, P., (2014). "Pengaruh Kepercayaan dan Kualitas Pelayanan terhadap Kepuasan Konsumen", Jurnal Marketing, Vol 321. No 69 Hal 117

www.bmtindragiri.co.id diakses tanggal 10 Mei 2020 jam 16.00 WIB.

Yulandari, A., (2009). "Analisis Pengaruh Kualitas Pelayanan GarudaIndonesia Airways Terhadap Kepuasan Konsumendi Kota Surakarta”. Jurnal Bisnis dan Kewirausahaan, Vol.2, No.3, Hal. 170110. 